\title{
ALTERAÇÕES NA QUALIDADE DA MADEIRA DE Eucalyptus grandis CAUSADAS PELA ADUBAÇÃO MINERAL
}

Carlos Roberto Sette $\mathrm{Jr}^{1 *}$, José Carlos de Deus $\mathrm{Jr}^{2}$, Mario Tomazello Filho ${ }^{3}$, Franciane Andrade de Pádua ${ }^{2}$, Francine Neves Cali1 ${ }^{1}$, Jean Paul Laclau ${ }^{4}$

*Autor para correspondência: crsettejr@hotmail.com

RESUMO: A diversificada e importante aplicação do lenho das plantações de eucalipto de rápido crescimento exige a análise do efeito dos fertilizantes minerais na qualidade do lenho. Dessa forma, objetivou-se, neste trabalho, avaliar as características anatômicas e a densidade aparente do lenho de árvores de Eucalyptus grandis, plantadas no espaçamento $3 \mathrm{~m}$ x $2 \mathrm{~m}$ e fertilizadas com potássio e sódio (no plantio, no $6^{\circ}$ e no $12^{\circ}$ mês). Foram selecionadas 15 árvores ( 5 árvores/tratamento) com 6 anos das quais foram cortadas amostras do lenho a 1,3 m de altura (DAP), para a análise das características anatômicas (fibras e vasos) e física (densidade aparente). Os resultados apontaram que as árvores de eucalipto que receberam aplicação de fertilizantes minerais não sofreram alterações significativas na densidade aparente média do lenho, com modelos dos perfis radiais comuns nos três tratamentos, caracterizados pelo aumento dos valores da região próxima à medula em direção à casca. A fertilização mineral influenciou as características anatômicas do lenho das árvores de eucalipto: o tratamento com sódio foi responsável pela diminuição na espessura da parede e pelo aumento no diâmetro do lume; no tratamento com potássio foram detectados vasos de maior diâmetro tangencial.

Palavras-chave: lenho, densidade, características anatômicas, fertilização, eucalipto; Eucalyptus grandis.

\section{WOOD QUALITY CHANGES CAUSED BY MINERAL FERTILIZATION}

\begin{abstract}
The diverse and important use of wood from fast growth eucalyptus plantations requires the analysis of the effect of mineral fertilizers on wood quality. The objective of this study was to evaluate the anatomical characteristics and wood density from Eucalyptus grandis trees ( $3 \mathrm{~m} \times 2 \mathrm{~m}$ spacing) fertilized with potassium and sodium (at planting, 6 th and 12th month). Fifteen (15) 6 years old eucalyptus trees were selected (5 trees/treatment), cut and wood samples at DBH $(1,3 \mathrm{~m})$ were taken for anatomical characteristics (fiber and vessels) and wood density analysis. Results showed that eucalyptus trees treated with mineral fertilizers did not show significant alteration in average wood density, with radial profile model common to all three treatments, characterized by a values increase in the region next to the pith, toward to bark. Mineral fertilization influenced wood anatomical characteristics: treatment with sodium was characterized by thinner walls and lumen larger diameter; in treatment with potassium, larger vessels were detected.
\end{abstract}

Keywords: stem wood; wood density; anatomy characteristic; fertilization; eucalyptus.

\section{INTRODUÇÃO}

A análise do histórico recente do setor florestal brasileiro evidencia uma fase importante entre os anos de 2000 e 2010, ocorrendo a consolidação da importância internacional do país no setor de florestas plantadas, sendo caracterizada pela ampliação das áreas de plantios e pela consolidação do processo de desenvolvimento tecnológico do setor, principalmente com relação ao ganho de produtividade (ASSOCIAÇÃO BRASILEIRA DE PRODUTORES DE FLORESTAS PLANTADAS - ABRAF, 2011). As espécies do gênero Eucalyptus destacam-se como as mais produtivas do setor florestal brasileiro, com produtividade média de $41,3 \mathrm{~m}^{3} / \mathrm{ha} /$ ano, fruto dos investimentos direcionados, principalmente, para o melhoramento genético e clonagem, preparo do solo e fertilização das árvores (ABRAF, 2011).

A fertilização mineral é a ferramenta comumente utilizada para modificar a qualidade do sítio e, assim, aumentar a taxa de crescimento das árvores. Embora a aplicação de fertilização mineral aumente significativamente, a taxa de crescimento das árvores de eucalipto (GAVA, 1997), são escassas as informações sobre o seu efeito nas propriedades e na qualidade da madeira, principalmente quanto à ação isolada dos nutrientes (SETTE JUNIOR et al., 2012).

1 Universidade Federal de Goiás - Goiânia, Goiás, Brasil

2 Universidade Federal de São Carlos - Sorocaba, São Paulo, Brasil

3 Universidade de São Paulo - Piracicaba, São Paulo, Brasil

4 Centre de Recherche Agronomique Pour le Développement - Montpellier, France

Cerne, Lavras, v. 20, n. 2, p. 251-258, abr./jun. 2014 
Em árvores de espécies de eucalipto de idades avançadas (até 30 anos), os resultados de pesquisas referentes ao efeito de fertilizantes minerais nas propriedades da madeira são controversos, com indicação de aumento (VIGNERON et al., 1995) e redução (SHIMOYAMA; BARRICHELO, 1989; WASHUSEN et al., 2005) da densidade do lenho. Em árvores de eucalipto jovens (1-4 anos) destacam-se os resultados de Bamber et al. (1982), Pereira e Araujo (1990) e Sette Junior et al. (2009a, 2009b), que não verificaram efeito significativo da fertilização mineral na densidade do lenho e nas dimensões das fibras. Nesse aspecto, Beadle et al. (2001) e Raymond (1998) destacam a importância de serem efetuadas análises das alterações das propriedades anatômicas e físicas da madeira das árvores de eucalipto com taxas de crescimento elevadas, em razão da fertilização mineral.

Por outro lado, a possibilidade de substituição total ou parcial do potássio por sódio na fertilização das plantações florestais, segundo Marschner (1991), é de interesse prático e científico, sendo que as principais fontes de $\mathrm{K}$ possuem $\mathrm{Na}$ em sua composição e o uso desses minerais representa uma economia de energia requerida no processo de purificação, permitindo uma redução no preço dos fertilizantes potássicos. Particularmente, para o Brasil que é o terceiro consumidor mundial, em 2006 foram utilizadas cerca de 3,4 milhões de toneladas de potássio, com produção no país de apenas 400 mil toneladas do nutriente (LACERDA, 1999). A substituição total ou parcial do $\mathrm{K}$ por $\mathrm{Na}$ diminuiria a dependência de fertilizantes importados, reduzindo os custos de implantação das florestas de eucalipto e, em consequência, os custos finais da madeira. Dessa forma, torna-se fundamental a determinação dos efeitos da aplicação do potássio e do sódio na qualidade da madeira produzida pelas árvores de eucalipto em plantações florestais, visando à futura substituição dos elementos químicos.

No presente trabalho, objetivou-se avaliar o efeito da aplicação do potássio e do sódio nas características anatômicas e na densidade aparente do lenho das árvores de Eucalyptus grandis.

\section{MATERIAL E MÉTODOS}

\subsection{Local do estudo}

As amostras de lenho foram coletadas de uma plantação de eucalipto localizada na cidade de Itatinga -
São Paulo, a $23^{\circ} 10^{\prime} \mathrm{S}$ e $48^{\circ} 40^{\prime} \mathrm{W}$, com $857 \mathrm{~m}$ de altitude. O clima da região é caracterizado como mesotérmico úmido (Cwa), segundo Köeppen, com precipitação média anual de $1.400 \mathrm{~mm}$ e temperatura média de $16,2^{\circ} \mathrm{C}$ e $28,6^{\circ} \mathrm{C}$ nos meses mais frios e mais quentes, respectivamente. O solo é do tipo Latossolo Vermelho Amarelo distrófico de textura média (200 $\mathrm{g} \mathrm{kg}^{-1}$ de argila) com a litologia composta por arenito, formação Marília, do Grupo Bauru.

\subsection{Delineamento experimental}

As propriedades do lenho das árvores de Eucalyptus grandis foram avaliadas de experimento de campo implantado em abril/2004 na Estação Experimental de Ciências Florestais da ESALQ/USP. O ensaio foi implantado em um delineamento experimental em blocos casualisados com 3 tratamentos e 4 blocos. Cada parcela foi constituída por 81 árvores, não sendo consideradas as duas linhas de bordadura, para evitar a influência dos tratamentos de fertilização das parcelas adjacentes.

$\mathrm{Na}$ área de implantação do projeto de pesquisa, foram distribuídos no solo $2.000 \mathrm{~kg} \cdot \mathrm{ha}^{-1}$ de calcário dolomítico, a lanço e sem incorporação. O potássio e sódio foram aplicados em 3 vezes no primeiro ano (1/3 no plantio, $1 / 3$ aos 6 meses e $1 / 3$ aos 12 meses). Os tratamentos receberam, também, $80 \mathrm{~kg}$ de $\mathrm{P}_{2} \mathrm{O}_{5}, 45 \mathrm{~kg}$ de $\mathrm{N}\left(\mathrm{NH}_{4}\left(\mathrm{SO}_{4}\right)_{2}\right)$ e $45 \mathrm{~kg} \cdot \mathrm{ha}^{-1}$ de FTE (BR-12) como fonte de micronutrientes. Na adubação de cobertura realizada no $6^{\circ}$ e $12^{\circ}$ mês pós-plantio foram aplicados $90 \mathrm{~kg} \cdot \mathrm{ha}^{-1} \mathrm{de}$ $\mathrm{N}\left(\mathrm{NH}_{4}\left(\mathrm{SO}_{4}\right)_{2}\right)$ e doses de $\mathrm{K}$ e Na, em função dos tratamentos, sendo (i) controle, sem aplicação de K; (ii) aplicação de $116 \mathrm{~kg} \cdot \mathrm{ha}^{-1}$ de $\mathrm{K}\left(\mathrm{K}_{2} \mathrm{O}\right)$ usada em solos semelhantes por empresa florestadora da região, constituindo-se em importante referência e (iii) aplicação de $68,5 \mathrm{~kg} \cdot \mathrm{ha}^{-1}$ de $\mathrm{Na}$ na forma de $\mathrm{NaCl}$.

\subsection{Seleção, corte e coleta das amostras do lenho das árvores de eucalipto}

Foram selecionadas 5 árvores de eucalipto com 6 anos, por tratamento de fertilização (controle, potássio e sódio), em um total de 15 árvores amostradas. As árvores de eucalipto foram cortadas e desramadas e foram seccionados discos do lenho a 1,3 m (DAP) para as determinações das dimensões das fibras (comprimento, espessura da parede, diâmetro do lume e largura total), vasos (diâmetro tangencial, frequência e área ocupada) e da densidade aparente.

Cerne, Lavras, v. 20, n. 2, p. 251-258, abr./jun. 2014 


\subsection{Densidade aparente do lenho por densitometria de raios $X$}

Dos discos do lenho na altura do DAP foram cortadas amostras diametrais $(20 \mathrm{~mm} \times 10 \mathrm{~mm}$, largura $\mathrm{x}$ altura $)$, coladas em suporte de madeira e seccionadas na direção radial (2,0 $\mathrm{mm}$ de espessura) em aparelho de dupla serra circular paralela. As seções radiais do lenho foram acondicionadas em câmara de climatização $\left(12 \mathrm{~h}, 20^{\circ} \mathrm{C}, 50 \% \mathrm{UR}\right)$ até atingir $12 \%$ de umidade. Para análise do perfil densitométrico, foi utilizado o equipamento QTRS-01X Tree-Ring Analyzer.

\subsection{Características anatômicas do lenho: dimensões das fibras e vasos}

Nas amostras de lenho na altura do DAP do tronco das 15 árvores (5 árvores/tratamento) foram demarcados e cortados corpos de prova (20 mm x $10 \mathrm{~mm}$, largura $\mathrm{x}$ espessura) em 3 posições radiais (direção medula-casca; 0 , 50 e $100 \%$ do raio) para o corte de seções transversais (15-20 $\mu \mathrm{m}$ de espessura) em micrótomo de deslizamento e para a obtenção de material para maceração pelo método de Franklin (JOHANSEN, 1940). Dos cortes histológicos e da suspensão de fibras foram preparadas lâminas histológicas temporárias, coletando-se imagens sob microscopia de luz (40x e 400x) para a mensuração das dimensões das fibras e vasos com o auxilio do programa de análise de imagem Leica Application atendendo às normas da IAWA(IAWA COMMITTEE, 1989).

\subsection{Análise estatística}

$\mathrm{Na}$ análise estatística dos resultados foi aplicado o programa JMP (STATISTICAL ANALYTICAL SYSTEM INSTITUTE - SAS INSTITUTE, 1997), sendo aferidos os "outliers" e a heterogeneidade da variância. Para os resultados, foi utilizada a análise de variância (ANOVA), verificando o efeito dos tratamentos de fertilização e das posições radiais do tronco e interações, sendo aplicado o teste de Tukey, ajustado a $95 \%$ de probabilidade.

\section{RESULTADOS E DISCUSSÃO}

\subsection{Densidade aparente do lenho por densitometria de raios $\mathrm{X}$}

Para a densidade aparente média do lenho, não foi verificada diferença significativa entre os tratamentos de fertilização. Esse resultado sugere que a substituição do
K pelo Na na fertilização de plantações de eucalipto pode ser adotada sem que a densidade, parâmetro importante de qualidade do lenho, se altere. Cabe ressaltar que outros parâmetros de qualidade do lenho e de crescimento das árvores devem ser avaliados para que a substituição total ou parcial do K pelo Na seja adotada na implantação florestal. Apesar do efeito não significativo, as árvores do tratamento controle, que não receberam adição de $\mathrm{Na} e \mathrm{~K}$, apresentaram densidade aparente do lenho ligeiramente superior $\left(0,50 \mathrm{~g} . \mathrm{cm}^{-3}\right)$ em relação ao lenho das árvores do tratamento com potássio e com sódio $\left(0,47 \mathrm{~g} . \mathrm{cm}^{-3}\right)$ (Tabela 1). Os valores de densidade aparente máxima do lenho das árvores de eucalipto para os três tratamentos de fertilização não foram estatisticamente significativos. Os valores médios de densidade aparente mínima e máxima do lenho variaram de $0,33-0,34 \mathrm{~g}_{\mathrm{cm}} \mathrm{cm}^{-3}$ e $0,76-$ 0,90 g. $\mathrm{cm}^{-3}$ nos tratamentos controle, potássio e sódio, sendo que a amplitude de variação da densidade aparente do lenho indicou a presença de alternância de faixas de crescimento no lenho detectadas pela precisão do método de densitometria de raios $\mathrm{X}$.

Os valores de densidade aparente média do lenho das árvores de eucalipto com 6 anos de idade $(0,47-0,50$ g. $\mathrm{cm}^{-3}$ ) foram similares aos encontrados por Sette Junior et al. (2009a, 2009b, 2012). Contudo, esses valores são inferiores aos determinados por Tomazello Filho (2006) para esta e outras espécies de eucalipto, com idades de 10-20 anos $\left(0,65-0,70\right.$ g. $\left.\mathrm{cm}^{-3}\right)$, pela mesma técnica de densitometria de raios X. Essa diferença está associada aos teores de madeira juvenil e adulta e à idade das árvores, sendo que a madeira juvenil formada no lenho de árvores jovens apresenta, geralmente, menor densidade que a

Tabela 1 - Densidade aparente média, máxima e mínima do lenho das árvores de eucalipto por tratamento de fertilização.

Table 1 - Mean, maximum and minimum wood density of the eucalypt trees per fertilization treatments.

\begin{tabular}{cccc}
\hline \multirow{2}{*}{ Tratamentos } & \multicolumn{3}{c}{ Densidade aparente $\left(\mathrm{g} / \mathrm{cm}^{3}\right)$} \\
\cline { 2 - 5 } & Média & Máxima & Mínima \\
\hline Controle & 0,50 a $(0,01)$ & 0,76 a $(0,05)$ & 0,34 a $(0,03)$ \\
$\mathrm{K}$ & 0,47 a $(0,03)$ & 0,85 a $(0,06)$ & 0,25 b $(0,05)$ \\
$\mathrm{Na}$ & 0,47 a $(0,02)$ & 0,90 a $(0,08)$ & 0,33 ab $(0,03)$ \\
\hline
\end{tabular}

Médias seguidas do desvio padrão; médias seguidas da mesma letra, na coluna, não diferem entre si pelo Teste de Tukey $(\mathrm{p}<0,05 \%)$.

Cerne, Lavras, v. 20, n. 2, p. 251-258, abr./jun. 2014 
das árvores adultas (HILLIS; BROWN, 1984). Como citado anteriormente, as pesquisas referentes ao efeito de fertilizantes minerais nas propriedades da madeira de árvores de eucalipto de idades avançadas (até 30 anos) indicam o aumento (VIGNERON et al., 1995) e a redução (SHIMOYAMA; BARRICHELO, 1989; WASHUSEN et al., 2005) da densidade do lenho. Em árvores jovens (1-4 anos) de eucalipto, destacam-se os resultados de Bamber et al. (1982), Pereira e Araujo (1990) e Sette Junior et al. (2009a, 2009b), que não verificaram efeito significativo da fertilização mineral na densidade do lenho, corroborando os resultados encontrados neste trabalho.

Os perfis radiais de variação da densidade aparente do lenho permitem verificar importantes e significativas respostas do crescimento das árvores de eucalipto, nos diferentes tratamentos (Figura 1). Observam-se, por exemplo, maiores valores de densidade (picos) delimitando uma região interna do lenho (medula até 2,5-5,0 cm do raio) e externa (raio de 5,0;5,7 e 8,0 cm nos tratamentos controle, potássio e sódio, respectivamente) do tronco das árvores de eucalipto. A região interna do lenho do tronco é comum a todas as árvores de eucalipto, apresentando modelo de variação da densidade aparente do lenho semelhante, constituída pela madeira juvenil e sem a demarcação das camadas de crescimento. Nessa região, a densidade aparente mínima e máxima do lenho é de 0,25 0,35 e de $0,55-0,65$ g.cm ${ }^{-3}$, respectivamente. Na região externa do lenho do tronco das árvores de eucalipto o modelo de variação da densidade aparente é característico nos três tratamentos, com nítidas camadas de crescimento e com valores mínimos de $0,30-0,35 \mathrm{~g} \cdot \mathrm{cm}^{-3}$ e máximos de $0,75-0,80$ g. $\mathrm{cm}^{-3}$.

Os perfis de densidade - por densitometria de raios $\mathrm{X}$ - do lenho das árvores de eucalipto das classes de área basal média de cada tratamento de fertilização (Figura 1) evidenciam modelo de variação caracterizado por valores crescentes da medula para a casca $(0,40-0,55$ para 0,75-0,80 g. $\left.\mathrm{cm}^{-3}\right)$, com algumas flutuações de densidade aparente, decorrentes das variações de diâmetro/frequência dos vasos e de faixas de fibras de parede mais espessas.

Esses perfis de densidade do lenho apresentam similaridade com os resultados apresentados por Tomazello Filho (2006), para árvores de eucaliptos com idades mais avançadas (10 a 30 anos), com menores valores de densidade do lenho proveniente da região interna do tronco (madeira juvenil), seguida de região de transição e, na sequencia, aumento gradativo da densidade em direção à casca (madeira adulta). Portanto, o modelo de variação da densidade aparente do lenho das árvores de eucalipto, com 6 anos, caracteriza-se pela presença de madeira juvenil e do surgimento da madeira de transição.

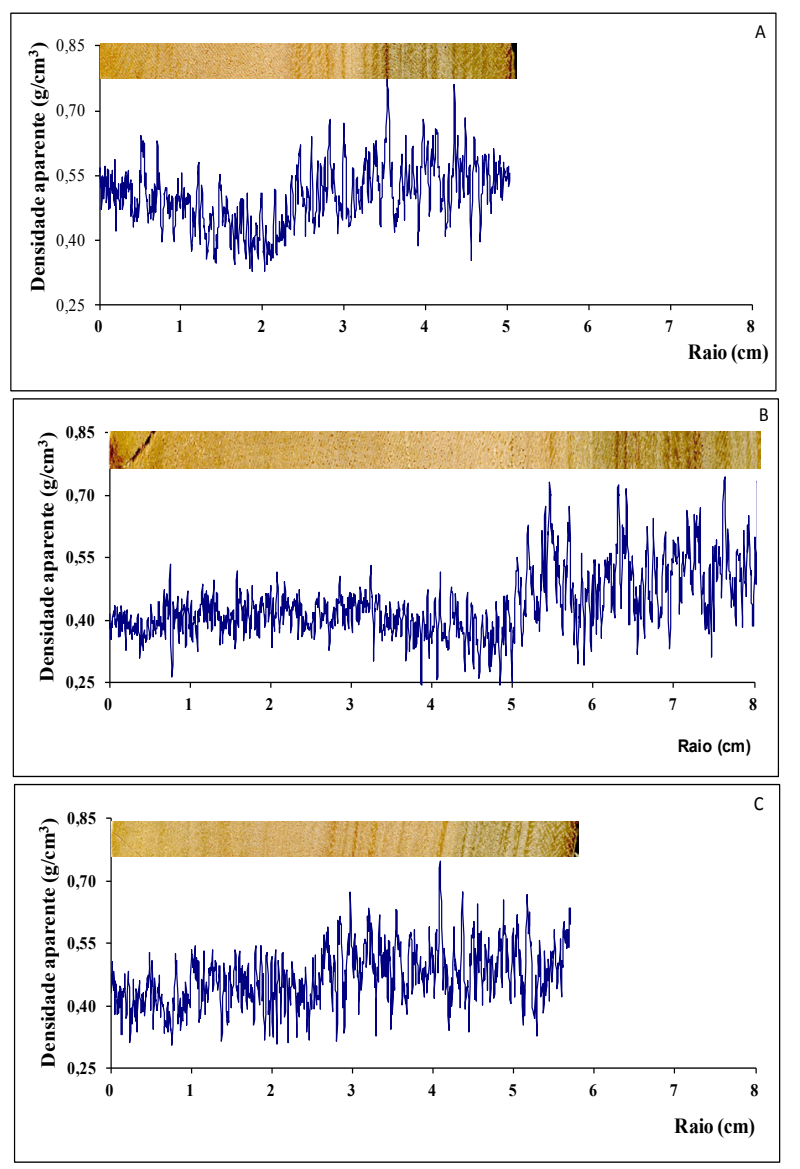

Figura 1 - Variação radial da densidade aparente média do lenho da árvore de eucalipto de classe de área basal média dos tratamentos (A) controle, (B) potássio e $(\mathrm{C})$ sódio.

Figure 1 - Radial variation of wood density in eucalypt tree for medium basal area of the treatment (A) control, (B) potassium and $(C)$ sodium.

\subsection{Características anatômicas do lenho: dimensões das fibras e vasos}

No lenho das árvores de eucalipto fertilizadas com sódio, foram detectadas fibras com parede celular menos espessa $(3,26 \mu \mathrm{m})$ e maior diâmetro do lume $(10,20 \mu \mathrm{m})$, com diferença estatisticamente significativa em relação aos tratamentos controle $(3,60$ e 9,50 $\mu \mathrm{m})$ e com aplicação

Cerne, Lavras, v. 20, n. 2, p. 251-258, abr./jun. 2014 
de potássio (3,49 e 9,70 $\mu \mathrm{m})$. O aumento da espessura da parede das fibras no tratamento controle conferiu ao lenho maior densidade aparente, podendo afetar, por exemplo, o rendimento da celulose, a resistência físico mecânica do papel, a produção e a qualidade do carvão etc (SHIMOYAMA; BARRICHELO, 1989). A largura e o comprimento médios das fibras nos tratamentos de fertilização controle, potássio e sódio foram de 16,70 e $879,12 \mu \mathrm{m} ; 16,64$ e $912,94 \mu \mathrm{m}$ e 16,71 e $839,15 \mu \mathrm{m}$, respectivamente, com diferenças não significativas entre os tratamentos.

Os valores de largura, espessura da parede, diâmetro do lume e comprimentos de fibras, obtidos neste estudo são próximos dos encontrados por Sette Junior et al. (2009a, 2009b), Tomazello Filho (2006). Contudo, esses valores são diferentes dos apresentados por alguns autores, que analisaram, no entanto, árvores de Eucalyptus spp com idades mais avançadas e com madeira de transição e adulta já formadas no seu lenho. Como exemplo, Tomazello Filho (1985) avaliou árvores de Eucalytpus grandis com 10 anos, obtendo fibras com comprimento, largura, espessura e diâmetro do lume de $1200,23,5,4$ e 12,2 $\mu \mathrm{m}$, respectivamente. Com relação à menor variação da largura das fibras no lenho das árvores dos três tratamentos (Figura 2B), alguns autores, como Larson (1969) e Zobel e Buijtenem (1989), mencionam a teoria da independência dos processos fisiológicos da formação do lenho. Esta indica que a dimensão das fibras depende da pressão de turgescência no interior da célula e das auxinas produzidas na copa das árvores e que induzem maior plasticidade da sua parede primária. Dessa forma, maiores pressões de turgescência e concentração de auxinas induzem a formação de células de maior dimensão, logo após a divisão das células iniciais do câmbio, como as do lenho inicial das árvores de coníferas e de folhosas. Segundo Shimoyama e Barrichelo (1989), práticas silviculturais com propósito de acelerar o crescimento das árvores tendem a formar lenho com parede celular menos espessa e, consequentemente, com menor densidade, pois estas aceleram o processo de divisão celular, causando diferenças em seu desenvolvimento.

O efeito da fertilização nas dimensões das fibras do lenho de árvores de eucalipto tem sido reportado na literatura sem, no entanto, haver consenso dos resultados. Sette Junior et al. (2009b) e Shimoyama e Barrichelo (1989) detectaram a diminuição do comprimento das fibras com aumento da taxa de crescimento das árvores de eucalipto fertilizadas. A variação das dimensões das fibras nas três posições radiais $(0,50$ e $100 \%)$ no DAP do tronco das árvores de eucalipto aos 6 anos é apresentada na Figura 2. Com relação ao comprimento das fibras (Figura $2 \mathrm{~A}$ ), observa-se uma tendência de aumento significativo no sentido radial (medula-casca), independentemente do tratamento de fertilização aplicado, com menores valores próximos à medula $(800 \mu \mathrm{m})$, seguido de um aumento em direção à casca $(1050 \mu \mathrm{m})$. Da mesma forma, para a largura e diâmetro do lume das fibras (Figura 2B, D, respectivamente), verifica-se um aumento significativo das suas dimensões com a posição radial. Para a espessura da parede das fibras (Figura 2C), observa-se um comportamento ligeiramente diferente com valores constantes/decrescente da posição $0 \%$ para a $50 \%$ do raio, crescendo desse ponto até a posição $100 \%$ do raio.

A literatura científica reporta extensa lista de artigos relatando a variação das dimensões das fibras, no sentido radial do lenho de árvores de diferentes espécies de eucalipto e condições de crescimento. Diversos modelos de variação radial das dimensões das fibras no lenho das árvores de eucalipto tem sido reportado, indicando, entre outros, os observados neste estudo (SETTE JUNIOR et al., 2009a, 2009b, 2012; TOMAZELLO FILHO, 1985). O diâmetro dos vasos foi significativamente maior no lenho das árvores fertilizadas com potássio $(119 \mu \mathrm{m})$ em relação ao controle $(102 \mu \mathrm{m})$ e ao sódio $(104 \mu \mathrm{m})$. Essa diferença está relacionada, provavelmente, às maiores exigências de transporte de seiva bruta pelas árvores de maiores dimensões, fertilizadas com K. Os demais parâmetros dos vasos não apresentaram diferenças significativas entre os tratamentos de fertilização: a frequência foi menor $(15,7$ vasos. $\mathrm{mm}^{-2}$ ) e a área ocupada foi maior (14\%) no lenho das árvores fertilizadas com potássio.

A formação de vasos de maior diâmetro e menor frequência no lenho de árvores de Eucalyptus grandis de 2,5 anos, induzidas a altas taxas de crescimento pela aplicação de fertilizantes foi reportada por Bamber et al. (1982) na Austrália. Por outro lado, Tomazello Filho (2006) não observou significativas diferenças das dimensões dos vasos no lenho de árvores de Eucalyptus grandis $\mathrm{x}$ urophylla submetidas a tratamentos de fertilização e irrigação. Os resultados obtidos neste estudo corroboram os encontrados por Drew et al. (2009) e Sette Junior et al. (2009b) para as árvores de eucalipto: árvores de rápido crescimento apresentam poucos vasos e de grande diâmetro, comparadas com as de crescimento lento.

Cerne, Lavras, v. 20, n. 2, p. 251-258, abr./jun. 2014 
Para os três parâmetros analisados dos vasos, foi detectado um efeito significativo da posição radial, sendo observado um aumento no diâmetro tangencial (75-112 para $105-130 \mu \mathrm{m})$ e na área ocupada (11-13 para 13-16\%) e uma redução na frequência (17-20 para 12-15 vasos. $\mathrm{mm}^{-2}$ ) dos vasos da medula para a casca (Figura 3). $\mathrm{O}$ modelo de variação radial de diâmetro tangencial, da
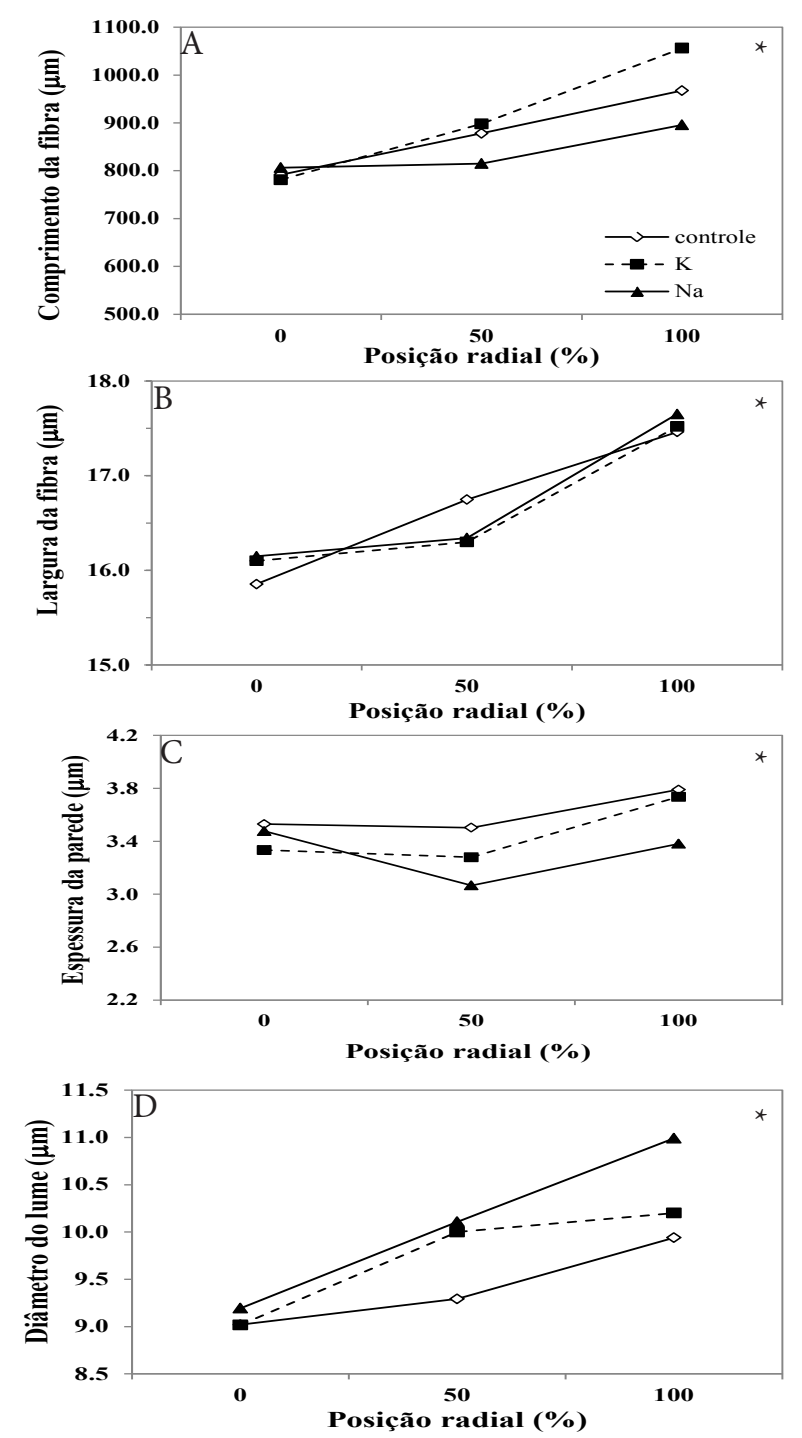

Figura 2 - Variação das dimensões das fibras no sentido radial: comprimento (A) largura (B), espessura da parede (C) e diâmetro do lume (D) por tratamento; ${ }^{\star}$ significativo $(\mathrm{p}<0,05)$.

Figure 2 - Variation of the fiber dimensions in the radial direction: length $(A)$, width $(B)$, wall thickness $(C)$ and lumen diameter $(D)$ per treatment; ${ }^{*}$ significance $(p<0,05)$.

Cerne, Lavras, v. 20, n. 2, p. 251-258, abr./jun. 2014 porcentagem da área ocupada e da frequência são comuns para as espécies de Eucalyptus spp (SETTE JUNIOR et al., 2012; TOMAZELLO FILHO, 1985, 2006). Os modelos de variação radial encontrados podem influenciar nas propriedades tecnológicas, entre elas, na penetração do licor e de preservativos, na densidade do lenho, na qualidade de papéis de impressão, etc.

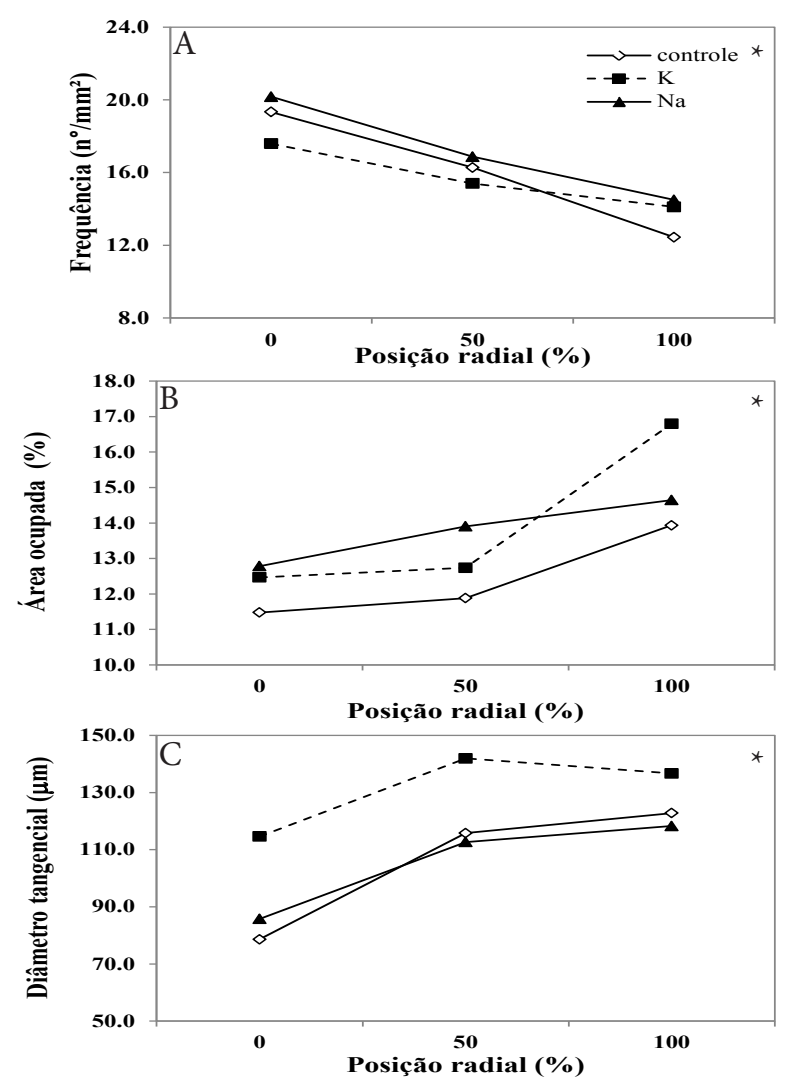

Figura 3 - Variação das dimensões dos vasos no sentido radial: frequência (A), \% de área ocupada (B) e diâmetro tangencial (C) por tratamento; ${ }^{*}$ significativo $(\mathrm{p}<0,05)$.

Figure 3 - Variation of the vessels dimensions in the radial direction: frequency (A), \% of area occupied (B) and tangential diameter $(C)$ per treatment; ${ }^{*}$ significance $(p<0,05)$.

\section{CONCLUSÃO}

As árvores de eucalipto que receberam aplicação de potássio e sódio não sofreram alterações significativas na densidade aparente média do lenho. A substituição do K pelo Na na fertilização de plantações de eucalipto pode ser adotada sem que a densidade, parâmetro importante de qualidade do lenho, se altere. 
A fertilização mineral influenciou as características anatômicas do lenho das árvores de eucalipto: a aplicação de sódio promoveu fibras com parede celular menos espessas e maior diâmetro do lume; no tratamento com potássio foram detectados vasos de maior diâmetro tangencial.

\section{AGRADECIMENTOS}

À Fundação de Amparo à Pesquisa do Estado de São Paulo (FAPESP) pelo financiamento dessa pesquisa, ao Departamento de Ciências Florestais da ESALQ/USP, especialmente ao Rildo Moreira e Moreira e à Maria Aparecida R. Bermudez e ao prof. Fábio Camargo Abdalla da UFSCar, campus Sorocaba, pelo apoio.

\section{REFERÊNCIAS}

ASSOCIAÇÃO BRASILEIRA DE PRODUTORES DE FLORESTAS PLANTADAS. Anuário estatístico da ABRAF 2011: ano base 2010. Brasília, 2011. 130 p.

BAMBER, R. K.; HORNE, R.; GRAHAM-HIGGS, A. Effect of fast growth on the wood properties of Eucalyptus grandis. Australian Forestry Research, v. 12, n. 2, p. 163-167, Dec. 1982.

BEADLE, C.; BANHAM, P. W.; WORLEDGE, D.; RUSSEL, S. L.; HETERINGTON, S. J.; HONEYSETT, J. L.; WHITE, D. Effect of irrigation on growth and fibre quality of Eucalytpus globulus and Eucalyptus nitens. Appita Journal, v. 54, n. 2, p. 144-147, 2001.

DREW, D. M.; GEOFFRE, Y. M.; DOWNES, G. M.; GRADY, A. P.; READ, J.; WORLEDGE, D. High resolution temporal variation in wood properties in irrigated and non-irrigated Eucalyptus globules. Annals of Forest Science, Les Ulis, v. 66, p. 1-10, 2009.

GAVA, J. L. Efeito de adubação potássica em plantios de E.grandis conduzidos em segunda rotação em solos com diferentes teores de potássio trocável. IPEF, Piracicaba, v. 11, n. 30, p. 89-94, abr. 1997.

HILLIS, W. E.; BROWNA, G. Eucalyptus for wood production. Sydney: Academic, 1984. 434 p.

IAWA COMMITTEE. IAWA list of microscopic features for hardwood identification. IAWA Bulletin, Leiden, v. 10, n. 3, p. 219-332, 1989.

JOHANSEN, D. A. Plant microtechnique. New York: MacGraw-Hill, 1940. 533 p.
LACERDA, M. P. Porque os fertilizantes subiram tanto? Hortifruti Brasil, v. 7, n. 77, p. 8-15, mar. 1999.

LARSON, P. R. Wood formation and the concept of wood quality. New Haven: Yale University, 1969. 54 p. MARSCHNER, H. Mineral nutrition of higher plants. 2nd ed. London: Academic, 1991. 889 p.

PEREIRA, H.; ARAUJO, C. Raw-material quality of fast grow Eucalyptus globulus during the first year.

IAWA Bulletin, Leiden, v. 11, n. 4, p. 421-427, 1990.

RAYMOND, C. A. Wood properties, silviculture and growth: a review of published literature for eucalypts. Melbourne: CRC, 1998. 18 p. (Technical Report, 6).

SETTE JUNIOR, C. R.; ROSADA, I.; TOMAZELLO FILHO, M.; YAMAJI, F. M.; LACLAU, J. P. Efeito da idade e posição de amostragem na densidade e características anatômicas da madeira de Eucalyptus grandis. Revista Árvore, Viçosa, v. 36, p. 1183-1190, 2012.

SETTE JUNIOR, C. R.; TOMAZELLO FILHO, M.; LOUSADA, J. L. P. C.; LACLAU, J. P. Efeito da aplicação de fertilização nitrogenada e lodo de esgoto nas características da madeira juvenil em árvores de Eucalyptus grandis. Cerne, Lavras, v. 15, p. 303-312, 2009a.

SETTE JUNIOR, C. R.; TOMAZELLO FILHO, M.; LOUSADA, J. L. P. C.; LACLAU, J. P. Efeito da aplicação de potássio e sódio nas características do lenho de árvores de Eucalyptus grandis W.Hill ex Maidenl, aos 24 meses de idade. Revista Floresta, v. 15, n. 3, p. 303-312, jul./set. 2009b.

SHIMOYAMA, V. R. S.; BARRICHELO, L. E. G. Densidade básica da madeira, melhoramento e manejo florestal. IPEF, Piracicaba, v. 6, n. 20, p. 1-22, ago. 1989.

STATISTICAL ANALYTICAL SYSTEM INSTITUTE. SAS/STAT user's guide. Version 6.08. Carry, 1997. v. 2, $846 \mathrm{p}$.

TOMAZELLO FILHO, M. Efeito da irrigação e fertilização nas propriedades do lenho de árvores de Eucalyptus grandis $\mathbf{x}$ urophylla. 2006. 135 p. Tese (Livre-Docência) - Escola Superior de Agricultura "Luiz de Queiroz", Piracicaba, 2006.

Cerne, Lavras, v. 20, n. 2, p. 251-258, abr./jun. 2014 
TOMAZELLO FILHO, M. Variação radial da densidade básica em estrutura anatômica da madeira do Eucalyptus saligna e Eucalytpus grandis. IPEF, Piracicaba, n. 29, p. 37-45, abr. 1985.

VIGNERON, J.; GERARD, J.; BOUVET, J. M.

Relationship between basic density and growth in a fertilization trial with clones of Eucalyptus hybrids in Congo. In: IUFRO CONFERENCE EUCALYPT PLANTATIONS: IMPROVING FIBRE YIELD AND QUALITY, 1., 1995, Hobart. Proceedings... Hobart: IUFRO, 1995. p. 68-71.

WASHUSEN, R.; BAKER, T.; MENZ, D.; MORROW, A. Effect of thinning and fertilizer on the cellulose crystallite width of Eucalyptus globulus. Wood Science and Technology, Berlin, v. 39, n. 7, p. 569-578, Oct. 2005.

ZOBEL, B. J.; BUIJTENEN, J. P. Wood variation: its causes and control. Berlin: Springer-Verlag, 1989. 361 p.

Recebido: 22 de março de 2012; aceito: 04 de setembro de 2013.

Cerne, Lavras, v. 20, n. 2, p. 251-258, abr./jun. 2014 